\title{
Protecting Related Creations to Fashion in the Framework of Literary and Artistic Property Rights of Iran and France
}

\author{
Sattar Zarkalam ${ }^{1} \&$ Amin Rooholamini ${ }^{1}$ \\ ${ }^{1}$ Faculty Member of Law Department, Shahed University, Iran \\ Correspondence: Sattar Zarkalam, Faculty Member of Law Department, Shahed University, Iran.
}

Received: September 15, 2017

Accepted: October 18, 2017

Online Published: November 29, 2017

doi:10.5539/jpl.v10n5p157

URL: https://doi.org/10.5539/jpl.v10n5p157

\begin{abstract}
In today's world where the process of development and the industry is evolving more rapidly than expected, the legal notions are going forward on their compliance in line with these developments. The increasing development of intellectual property rights and their samples is an example of this change. One of the most important issues and instances of this tendency in legal rights is associated with fashion productions and creations. France, as one of the greatest leading country in fashion industry since long time ago, has legally protected the dress and beautiful creations in the intellectual property rules and in the different time periods, under the various titles, including the drawings and models rights, industrial property rights, literary and artistic property rights. French jurisprudence has broadly interpreted the concept of the fashion industry and consequently, the dress and beauty creations that have evolved not only the goods, but all parties involved in the production of the fashion industry. In Iranian law also, although there is no progress in this field compared to French law, with an optimistic interpretation of the rules of its intellectual property, it can be associated with Droit d'-auteur rules in addition to the industrial property rights under different titles such as design and drawings, Applied artwork, folklore etc.
\end{abstract}

Keywords: fashion, fashion designers, dress and aesthetic creations, literary and artistic property rights

\section{Introduction}

One of the issues, which has been brought into legal literature of the countries along with the growth of industry and parallel to it, the progress of intellectual property rights, is the subject of fashion and consequently the creations and dress and aesthetic products as well as schemes and models, as the instances of fashion industry.

Literally, fashion means fresh taste and new method but it idiomatically refers to the sudden change in the taste of a group of people who tend to show a particular behavior or consume a particular good or follow a different style in their life temporarily (Bressé, P., 2004).

Through studying the French law and investigating the studies about intellectual property rights as well as the regulations associated with that, it has been tried since 1972 to legally protect aesthetic-dress creations dominated by fashion following different instances, such as the rights of schemes and models, Droit d'-auteur and relevant creations to seasonal industries (Ibid). In Iranian law also according to article 4 in the law of organizing fashion and dress approved in 2006, "the produced schemes and patterns, tissue and clothes based on Iranian-Islamic symbols have been included in protecting Droit d'-auteur and industrial property rights". However, there is somehow disagreement that under what circumstances relevant products to the fashion can be imagined and to what extent the capacities of intellectual property rights can protect this subject. Due to this, the raised questions in this paper are formed in the framework that firstly, how much are fashion-related products included? And the other one is that to what extent literary and artistic property rights enjoy legal capacity towards protecting these works and finally, under what circumstances the related creations to fashion can be protected if protecting these works is provable in artistic and literary property system. In order to this and to response the mentioned questions, conceptual framework of fashion has been firstly investigated and following that, possibility or impossibility of protecting associated products to fashion in artistic and literary property has been explained through stating the protectable examples and the conditions of protecting them by each one of two mentioned systems and in the end, a conclusion of what has been said is proposed. 


\section{Literature Review}

The fashion in a modern concept that despite having common instances in all societies, sometimes there can be some differences in its meaning due to the difference in the cultural-social infrastructures of the countries. As an example; what in Iran, having such a religious and national history, is interpreted as fashion is definitely different from what European and Western countries call it, but fashion and fashion victim seem to be different and due to proposing a comprehensive definition from fashion, existing differences should be considered related to the type of fashion victim not the thing which is considered as the definition and concept of fashion (Moghimi, 2007).

\subsection{The Definition of Fashion as a Lexis}

Fashion is a phenomenon especially for human society which has a close relationship with modernism concept. In another word, fashion has been appeared with societies' modernization because in previous eras, a concept as fashion and fashion victim wasn't tangible among people as today is. However, looking at history, this phenomenon can be observed among big civilizations of the world, as it is said about Sumerian women, using ornaments and luxury dresses have been significantly more common among wealthy women (Tavassoli, 2003).

Attention to the literal meaning of this concept beside its expression meaning greatly contribute understanding it. In order to this, a definition of a fashion word discussed by linguists is proposed.

Fashion is rooted in Latin Modus. This word was loaned in Iran after the First World War following the influence of Western civilization. Fashion word in Persian literature has been driven from the French language and means a temporary method which determines lifestyle, clothing style and so forth according to the taste of the people at that time (Dehkhoda, 1998). The point to be considered in this definition is temporality of the behavior. Therefore, it can be said that fashion refers to sudden and frequent taste change of all or some of people in a society (Mohammadnejad, 2005).

More precisely, fashion literally means fresh taste and new method, but it idiomatically refers to sudden change in the taste of a group of people, which leads to tending to do a particular behavior or consuming a particular product as well as following a particular style in their life. This word is close to the words such as modern, modernity and modernization. In Medieval Europe, this word used to be avoided and an innovative issue was described as "New" (Bayat, 2009). A new object or phenomenon was an innovative subject which belonged to the divine source and God creation and on the contrary, the phenomenon of fashion and modernity belonged to the secular source. Fashion was driven from human will for creation and was a concept near to "heresy" in Islamic culture, but simultaneous with eliminating tradition in the social affairs of Europe in enlightenment era, the words such as modern and fashion were also sanctified and became popular more than before (Ibid).

According to what French authors have written, fashion can be defined as an aesthetic criterion which has been accepted by a particular group of people in the society (Vivant, 2012). Also in some French general dictionaries, fashion has been defined as "fashion is a type of life and thinking particular style in a particular period of time or country or a place" (Rey, 2012).

As it can be seen in this definition, fashion has been defined so much generally that even include people's thinking type and style in a particular period of time. The other important point about the above-mentioned definition is that mentioning the words such as "period", "country" and "place" reminds us the relativity and temporality of this concept (DUPONT- DELESTRAINT, 2008).

Although, whenever fashion and its concept is discussed, its aesthetic issue is more considered, including the thinking type in a particular place and time period as fashion is a strong reason for regarding this subject in the framework of intellectual property rights. More precisely, suggesting the definition of words which has been proposed by France from fashion, it is concluded that a subject may not be considered as an aesthetic concept, but, according to protecting regulations related to fashion in intellectual property, it can be protected. As it will be followed, the subjects such as patent which has industrial approach more than aesthetic one are considered included in protecting rules in case of some of products and creations.

\subsection{Fashion Concept as an Expression}

After investigation fashion as Lexis, the position of this concept should be now explained in the legal literature of Iran and France. Attention to this subject is noticeable because it established the main body of thinking style on the subject of the study.

In fact, merely with recognizing the exact position of fashion concept in legal literature, its protective regulations can be identified and in this way, precise protect measures can be proposed for it.

Although Iran, in terms of its traditional and religious structure, has adjusted its legal regulation, according to 
jurisprudential and religious rules either, it hasn't lagged behind modern legal issues and has always tried to prove the compliance of these emerging concepts with jurisprudence meanwhile recognizing the innovative concepts. To propose a definition of this concept in Iran law, it can be said that "fashion, as a part of intellectual property rights' body, has included any types of dress and ornaments for the human body that, in the form of Droit d'-auteur and industrial property rights, includes financial and moral right for its owner and in case of violating these rights, its designer and creator can use civil and criminal sanction" (Pirouzfard, 2009). Also, according to what some French authors have written, fashion can be defined as "a concept with an aesthetic and artistic feature having criminal and civil sanction system in case of the violation that the owners of these works can enjoy legal protection against any kind of violation for their financial and moral rights"(Vivant, 2012).

\section{Results}

In this section, following two previous subjects, the samples of literary and artistic property rights related to fashion and the conditions of protecting relevant products to fashion industry will be investigated.

\subsection{Relevant Samples to Fashion in Literary and Artistic Property Rights}

In France, the rights related to Droit d'-auteur, which have been predicted in the first book of France intellectual property law approved in 1992, in addition to specific items, the list of works that can be protected as executive arts and relevant products to fashion, has gotten non-restrictive aspects.

First is that according to article L.111-1 and L.112-1 of abovementioned law, the creators of intellectual works, merely because of creating a literary and artistic work, is included in protecting intellectual property rights (the rights related to property about intangible and non-objective works) and all people can cite the mentioned rights. The components of this article is in fact equivalent with the content which has been stated in article 1 of the protecting the rights of authors, artists law as well as article 6 of the comprehensive bill on the protection of literary and artistic property rights (approved in 2014) in this field (Imami, 2007). In accordance with the provisions of the two above-mentioned laws, "the author, writer and artist, "creator" and what obtained through knowledge and art or their innovation; regardless of the way and method which is used in stating or emerging or creating it, are called "opus". Also, "the opuses are protected in terms of their creation and regardless of considering the method of proposing it".

The first point which is reminded about above subjects is that considering the prediction of protective work of Droit d'-auteur, the mere creation regardless of the process and the technique of proposing can be protected even without requiring explicit consideration of the legislator for relevant products to fashion industry according to this legal system, considering the conditions which will be mentioned as follows.

Also, according to paragraph 12 of article 1 of the law in protecting the rights of authors, writers and artists as well as paragraph 15 of article 3 in mentioned bill, "the works which are created from a combination of other protected ones in article 1 and 3 of this law, provided to have originality, can be protected. Hence; even if a work hasn't been considered under a special title in the list of these articles, merely having general conditions related to the Droit d'-auteur, will be protected (Shafiei, 2008) and therefore, protecting related rights to the fashion industry, provided having determined conditions, is justified through this.

Moreover, in the law of France and Iran and in the articles which have been allocated to Droit d'-auteur and its' protective works, there are some instances whose compliance with the concept of fashion and its products seem without any problem that each one is discussed below:

\subsubsection{Painting, Picture, Scheme and Any Kind of Decorative Works}

The mentioned cases in this paragraph have been protected by legislator both in Iran and France law. In fact, according to paragraph 7 of article L-112-2 of French Intellectual Property Law "drawing and painting..." are considered as the works which have been included in legal protect. In Iranian law also, paragraph 5 of article 1 in the Law of Protecting the Rights of Authors, Writers and Artists as well as paragraph 8 and 10 of article 2 in above-mentioned law, protecting these works has been mentioned.

To explain this type of protectable samples and its relationship with the fashion industry, firstly, it has to be said that according to the vote by French Supreme Court, the painting is noticeable in its public meaning and even its concept, about primary schemes of the dress, drawing primary images of dress and aesthetic creation have been also included in this concept (Cass.com, 1997). Moreover, mentioning any type of decorative works, considering an artistic feature of them, can be a type of aesthetic creations. It is necessary to mention that aesthetic creations are also used in two public and special concepts. This title in its public concept, in fact, includes all products which decorate human and causes the human body part to be out of its normal and natural mood. Therefore, aesthetic creations in its public concept, in addition to the decorative tool, even include a kind of jewelry as well 
and gets close to the concept of clothing creations. On the other hand, special title of aesthetic creations only includes cosmetics and doesn't include other samples. Of course, it needs to be said that the references to be referred to claims of infringement proceedings fashion in France, have always increased the expansion of including this type of intellectual products since even some tattoos tools on the body have been considered included in aesthetic creations as well (Demulin, 2007).

\subsubsection{Applied Artwork}

"By applied artwork, that type of art is meant that in addition to having an aesthetic and aesthetic aspect has consuming and applied aspect as well" (Pirouzfard, 2009). In French law, this expression has been used in paragraph 10 of article L.112-2 below protectable works. French Courts also, due to different votes, have considered the cases such as different types of salad dressing (Cass.com, 2000), opener (Cass.com, 1997) and egg dishes (Cass.com, 1996) in this frame. The mentioned subject, in Iran law, has been predicted by the legislator in paragraph 9 of article 2 in the law of protecting the rights of authors, writers and artists. However, Iranian legislator has merely mentioned the samples of applied artworks in mentioned paragraph and avoided using this expression for mentioned samples (Shafiei, 2008). Moreover, the other article, while fixing this flaw, in its paragraph 9 of article 2 and below protectable works, has considered applied artwork such as carpets and rugs and their drawings or other used arts in crafts or industrial goods" included in protecting. It should be also said that in paragraph 16 of article 1 in the mentioned bill, applied artwork means an artistic products work applied features or an artistic product which has been used in a suitable good such as being made manually or with industrial tools".

Therefore, although in current regulations of Iran literary and artistic property, citing the samples of this title, applied arts can be protected as a type of different products relevant to fashion, in case the mentioned bill has passed its legal process and becomes irrevocable, it can be claimed that, similar to France law, in Iran law also, applied artwork will be among the issues that explicitly without any ambiguity, its compliance with the concept of relevant creations to fashion can become possible.

\subsubsection{Designing the Form of Letters, Number or Other Symbols either Manually or Computerized}

The mentioned instances, in case the letters are interpreted as a type of shape in public concept, can be briefly considered as designing the shapes (symbols) and numbers. According to the current rules related to protecting literary and artistic property, paragraph 5 of article 2 on the law of protecting the rights of authors, writers and artists also include this concept somehow. The comprehensive bill of protecting artistic and literary property rights also has expanded this concept and in paragraph 13 of its article 2 has predicted designing above-mentioned samples "manually or computerized". Hence; this method of predicting by its developers can be considered as a forwarding process and in accordance with created developments in the field of industry and unavoidable entry of computers in all aspects of human life. Obviously, in case of using each instance of the mentioned ones in mentioned paragraphs of law and bill in the form of aesthetic-artistic work relevant to cloths and body ornaments or human life, can be protected in fashion framework either and as in France, number 1+3, which is a symbol of a rap music group in France, computerized on clothes has been considered protectable as the instance of relevant industries to the fashion (Cass.com, 2015).

\subsubsection{Works Based on Folklore Manifestations}

Folklore or the same public culture symbols have been consisted of two parts of folk, means people, and lore, means knowledge and in its expanded meaning, it includes the concept of "art folklore", "materialistic folklore", in which technological and technical aspect is involved. However, according to the definition which has been proposed by World Organizations of intellectual property in its recent documents about this expression, a new function of that was mentioned. On one hand, the technical and materialistic aspect of folklore was discussed as "traditional knowledge" and as a separated subject and on the other hand the notions of "traditional cultural manifestation" and "folklore manifestation" were considered as equivalent (Ghafouri, 2009).

Publically, folklore notion is considered in two frameworks of artistic folklore and technical folklore. Hence; the origin of this expression can be regarded in the area of literary and artistic property rights and industrial property rights. Obviously, what we mean by this phrase in this part, doesn't have any relation to industrial property rights and its artistic instance is merely meant. Moreover, since in relevant rights to folklore, artistic manifestations are considered in the framework of two fields of performing arts such as local dances, native theaters and performing arts such as embroidery and weaving (Habibi Dargah, 2009). Thus, on one hand, through investigating article 2 of law in protecting the rights of authors, writers and artists approved in 1969 which has stated the protectable works, about the compliance of fashion with protectable works of this law, it can be said that according to paragraph 5 of above-mentioned article, "painting and image and innovative geographical 
scheme and decorative writings and lines and any kind of decorative and visual works that have been created simply or combinational through any method" can be protected. Therefore, if painting, image and decorative work become as a dress or a part of the body, considering what said about the concept of fashion, can be protected as a sample of fashion in the framework of this paragraph. On the other hand, as paragraph 10 of mentioned articles has mentioned, innovative works related to folklore have been protected. Hence; if manifested as a dress or ornament on the parts of the body, folklore can be considered as an example of dress-aesthetic creations below fashion subject. More precisely, as some of French writers have reminded us, "folklore rights have a wide scope in which non- performing artworks (dress-aesthetic folklore) as one of its samples, is noticed by fashion industry because most of the dress and aesthetic creations designs are inspirational and affected by ethnic and local beliefs and meanwhile, because of having aesthetic and artistic feature, it can be proposed in fashion industry" (Desbois, 1992).

It has to be noticed that temporality of relevant products efficiency to fashion industry doesn't have any conflicts with the adaptation of folkloric rights to it because what as culture and ethnic and local beliefs respectedis, can be protected as folklore rights forever and merely manifesting these cultures and beliefs, considering the changes and manipulations which are conducted on it, in dress and aesthetic creations for a while and for a certain group, according to related regulations to fashion products, is protected. For example, some of the schemes or dresses which objectify a folk belief and thus are respected for those people forever may be combined with other dress creation by fashion designers or a scheme might be designed with a decorative good and becomes the criterion of using fashion and being updated by a particular group such as young people temporarily (Drexl, 2001).

However, facing this notion and inspiring with what goes on in relevant regulations to folklore rights in other countries, investigating authorities try to adapt this notion with the paragraphs of article L-112-2 of intellectual property law and they have adapted this concept with paragraphs 3, 4, 7 and 10 of the mentioned articles in different votes (Clarier, 2003).

\subsubsection{Relevant Creations to Seasonal Clothing Industry and Its Associated Products}

Compared to Iranian law, French law has acted very carefully and precisely in predicting the most important related sample to fashion industry. Abovementioned instances have been predicted in paragraph 14 of article L.112-2 of France intellectual property law. this paragraph of mentioned article state that "the products of seasonal clothing and jewelries industries... the mentioned industries, because of existing necessities in fashion regularly change and update the form and the shape of their products, especially in weaving, fur skins, lingerie, embroidery, footwear, leather gloves, producing new clothes or special for designing fashion, producing the accessories and boot industry as well as producing sofa fabric".

It has to be mentioned that, according to some French writers, predicting this paragraph means that French legislator has decided so that protecting relevant products to the fashion should be realized merely through stating mentioned samples in it and citing other cases and protectable works by intellectual property law is somehow a violation of his real intention (Montero, 1997).

But the fact is that noticing an issue won't suffice us from other cases and predicting mentioned paragraph doesn't mean that everything has been mentioned in this paragraph and there are no other things (Mestre, 1998).

To investigate abovementioned statements, it has to be said that the idea of recent group is closer to the reality and in fact according to the rule which exists in our law, "proving something won't deny the others". It is absolutely obvious that what exists in fashion industry isn't merely a completed form of a work but all levels from drawing the primary scheme of a product to final one which goes to the market, all are set in this form and thus, taking some examples out such as drawing, designing, the affairs which lead to creating art-applied work, using the manifestations of public culture in creating the work and all of these will be considered in this type (Ibid).

\subsection{The Conditions of Protecting Fashion in Literary and Artistic Rights of Iran and France}

Each one of intellectual works should have some conditions which the law (in general meaning) specify to be included in legal protects of intellectual property rights. Meanwhile, literary and artistic property rights, affected by the theory of art unity which has been predicted in article 1 in the law of protecting the rights of authors, writers and artists and article 6 of the bill as well as articles L-112-1 and L-513-2, has made simpler protecting system compared to industrial property rights.

In France law, according to the mentioned article, intellectual works merely because of the creation and regardless of any special ceremonies will be protected and moreover, as soon as proposing it to the national office of industrial property in form of the scheme and model, will enjoy the benefit of protecting fifth book that 
is related rights to the models and schemes (TGI, Paris, 1998).

It is clear that in this mood, the creator can enjoy two protecting frameworks simultaneously. In another word, even if he doesn't propose his produced good for the national office of industrial property, he will enjoy relevant rights to the system of Droit d'-auteur (Cass.com, 1999).

Despite what mentioned, associated works with literary and artistic property rights, in order to enjoy protecting Droit d'-auteur system, should provide two main conditions. Firstly, they should be appeared in form of a shape and secondly, they should have authenticity feature (Thriton, 2003).

Two mentioned conditions, in the case of dress creations or publically, the productions associated with fashion which is discussed in the framework of related rights to the plans and models also are necessary considering the theory of art unity.

\subsubsection{The Necessity of Crystallizing Fashion Creation in the Form of a Shape}

In France law similar to what exists in England, Italy and even the world system of literary and artistic property rights (Demulin, 2007), ideas aren't included in protect.

According to some experts, the major regulation which exists about legal protecting related works to literary and artistic property rights is the necessity of external crystallization of these works in the form of a shape. As the result, only if it has materialistic or non-materialistic visualization, it will be protected. This subject gets such importance that even the works which are stated and proposed verbally and in person enjoy the protecting system of Droit d'-auteur (TGI, 1996).

In case of related products to fashion industry also, the inattention of the presentation and the expression of the intellectual work can be cited according to one vote of the French town court. Based on this vote, the producer of a perfume who has produced his goods different from another producer even in terms of the type of packaging and appearance, though their odor is completely similar, is condemned (TGI, 2006). Also, according to another idea, the type of proposing and showing dress creations at a fashion show by models imitating rival's fashion show is considered violating intellectual rights of the initial fashion designer (TGI, 2001).

It has to be reminded that the principle of ideas supportability hasn't been noticed enough in Iranian and French literary and artistic property rights and only considering the content of article 1 of the law in protecting the rights of authors, writers and artists that define the work as "what appears from knowledge and art and with their innovation regardless of the method or way which has been used in the statement or territory or creating it", it can be well clarified that creation, statement and creation are the conditions of protecting a work and merely having an idea won't be protectable (Zarkalam, 2008).

It should be also said that the bill of protecting literary and artistic property rights has also followed mentioned policy in this field and hasn't stipulated important principle of protecting ideas. More precisely, article 6 of the mentioned bill repeats the same thing which article 1 has stated. In France law also, according to articles L-111-1 that have only considered creating a work protectable and also article L-111-2 of mentioned law that considers creating a work as the condition of protecting regulations for creator, introduces work creation as the condition for protecting it and protecting only ideas has been eliminated from this order.

Of what has stated, it can be concluded that protecting related creations to the fashion industry, as one of protected samples in literary and artistic property rights, also follows lack of protecting ideas and legal condition of protecting these works is merely in their crystallization in the form of an external manifestation, in the broad sense.

\subsubsection{Having Feature of Originality and Novelty}

One of other necessary conditions in protecting related creations to fashion is having the feature of originality and novelty. More precisely, it can be said that "the work is the product of human original intellectual free attempt which has been stated on a particular form and shape" (Imami, 2007). The word, novelty in the dictionary has numerous definitions, including that genuine has been interpreted as having a history and root (Dehkhoda, 1998). Legally, originality isn't that much different from its dictionary meaning. In fact, according to what common is about originality in legal literature, the work is considered original that is created by the creator and was born from his intellectual leakages (Zarkalam, 2008).

According to the France law in interpreting the original expression, there is a kind of disagreement. Some people believe that originality should have personal aspect (Dupont, 2008), on the contrary the other believe that a work is considered original when it has typically novelty. More precisely, being original in the typical notion, more than noticing the manifestation of the creator, notices the created work by him (Ibid). However, according to 
article L-112-1, even if the work is applied one, originality isn't ruled out.

In Iran law, according to articles 1 and 2 of law in protecting the rights of authors, writers and artists, work originality has been predicted by Iranian legislator under the title of being innovative. However, there is no criterion to explain this concept. On the other side, the comprehensive bill of protecting literary and artistic property rights, in addition, that in paragraph 1 of its article 1 considers a creation included these regulations that have been expressed original, in paragraph 20 of the same article; the originality criterion has been somehow specified. According to the mentioned paragraph "original means whatever is driven by the creativity of the creator without imitating others, though, isn't new in terms of subject or content".

\subsubsection{The Distinction between Originality and Novelty}

As it was previously mentioned, some of the jurists have considered originality personally and some others typically. However, it has to be said that typical originality in a work means the same novelty that is used in industrial property rights while according to public rules of intellectual property. Originality in the strict sense of the word is equivalent with the same personal criterion. In fact, considering a creation original in literary and artistic property rights, the regulation of no imitation should be considered though it existed before and lacked novelty (Azéma, 2011).

While according to public regulation in literary and artistic property rights, merely having originality suffices in protecting intellectual creations, French judicial procedure, in case of applied artworks and especially about related products to fashion, has also unanimously considered novelty necessary (Cass.com, 2005). In fact, the above-mentioned condition means that associated creation with fashion industry not only has to be original, but it shouldn't be the issue of priority and the presentation by someone else in any of its components (TGI, 1995).

Despite what expressed, although applying Droit d'-auteur on applied artworks has been controversial for a long time and finally has been predicted through the theory of art unity according to article L-112-1 of this country, however, still some French jurists haven't been convinced into having personality symbol towards the works having applied aspect (Dupont, 2008).

It should be said that according to the ideas by the Supreme Court of France about the criterion of originality towards associated products with fashion, shorten a skirt or cutting the sleeve of a shirt that already has existed doesn't include originality notion and created work hasn't been considered original (Cass.com, 2001; Cass.com, 2004). Also Supreme Court in another theory considered combining the new colors in a work with the colors of a cloth that has already existed, a criterion for the originality of the work (Cass.com, 1986).

\subsubsection{The Distinction between Originality and Quality}

Unlike originality, the quality of a work isn't considered as a criterion for separating protected works because the quality is a sudden issue and considering it as a criterion in literary and artistic works will have dangerous consequences because it causes personal evaluation to be involved in executing the law. Therefore, injustice will occur (Colombe, 2011). However, it has to be said that in a French judicial procedure, the legislator sometimes interferes the notion of quality in the cases they cannot discard their personal evaluation. As an instance, in evaluating the titles of original, quality is investigated (Ibid). Moreover, in associated products with fashion, considering the general satisfaction of consumers with high-quality products, this criterion joins the notion of originality.

It is concluded from what explained in this section that firstly, the notion of originality in literary and artistic rights should be considered in its personal criterion and secondly, in the productions related to fashion, especially associated creation with applied artworks, according to what exists in judicial procedure of France, public rule should be discarded and novelty criterion should be also considered as the condition for protecting these works besides originality.

\subsection{Duration of Protection}

Obviously, associated products to the fashion industry, as one of intellectual property rights types, based on that the type of exclusive right is financial or spiritual, can be protected in a specific time period. Although, the duration of protecting associated works with fashion, because of the nature driven from thinking, is in the framework of predicted legal protection in the intellectual property system, according to some scholars in France law, "associated creations with fashion, since are considered seasonal industry and thus dominate the market in a particular and temporary period of time, so considering the same feature, the type and rate of protecting them is better not to be as a predetermined time period and in case of violation and recognizing the time of protect, investigating authorities notice more temporary functions of this industry as well as the general interest of consumers of these products. However, and despite this theory seems somehow correct, it has to be claimed that 
legal regulations in each field and subject should have a specific framework and accepting such an idea causes that the basis of predicting legal rules that is organizing people's affairs and the problems of society is involved with Anxiety and non-discipline and its embedded target won't be suitable.

Therefore, related rules to the duration of protecting associated creations with fashion also are better to have a special framework according to what common is in the intellectual property rights system in terms of financial or spiritual.

\subsubsection{Moral Rights}

Despite lack of an accurate and comprehensive definition from moral rights in the Iranian law system, it has to be said that such a right has been recognized by the legislator in the regulations related to literary and artistic property rights. More precisely, Iranian legislator, in the position of identifying the moral right of the author, instead of the definition, has sufficed to stating the features and some of its instances. Of these cases, articles 3 , 17 and 18 of law in protecting the rights of authors, writers and artists about respecting the name and position of creator and article 19 of the above-mentioned law about the right to the custody of the work can be mentioned. Based on legal regulations of Iran and along with other modern legal systems, the duration of protecting moral right of creators in associated creations with fashion should be considered without limitation. Due to this, article 4 of the above-mentioned law can be mentioned in accordance with which the moral right of creator should be considered without time and location limitation. Moreover, according to article 29 of the comprehensive bill of protecting literary and artistic property rights also, this right is considered without any dependency on time and place with this supplementary explanation that applying the mentioned right after the death of creator on the heir, or the Ministry of Culture and Guidance. The notion of moral right in France refers to the early 19th century and it emerged by French revolutionists within 1791 and 1793 (Zarkalam, 2008). It has to be mentioned that in the law of this country also, moral right of the creator (fashion) according to paragraph 2 of article L-121-1 has been recognized and its duration is predicted lifelong.

\subsection{Economic Rights}

Another right, which the creator enjoys it because of his intellectual creation is financially right towards the work. Anyone who intellectually creates in the fashion industry, in addition, to gain honor, expects to have economic benefits of the work. As it was previously mentioned, considering the nature of relevant creations with the fashion industry, below the rule of intellectual property rights, the duration of protecting these works is better to be determined. In this field, it has to be said that according to article 4 of law in organizing fashion and clothes (approved in 2006), that is somehow a specific rule in his field, has enforced this belief and thus, it should be claimed that the duration of protecting these works and creations of fashion industry based on what article 12 of law in protecting the rights of authors, writers and artists predicts, includes 30 years but as some of the scholars have reminded correctly, in evaluating the duration of protecting economic rights in Iranian law, and compared to other Droit d'-auteur systems, 30 years is a short time and maybe because of this, the developers of the comprehensive bill in protecting literary and artistic property rights, in its article 24 , have increased it to 50 years. However, it should be noticed that considering the importance of intellectual properties, mentioned time is considered very low compared to what exists in French law in this field.

\section{Conclusion}

According to what concluded in this study and also using the judicial procedure of France in this case, fashion notion is recommended to be interpreted in a wide meaning and beyond final product which is proposed to the consumer. More precisely, although in general mood, the range of including the instances of fashion is put below two main titles of dress and aesthetic creations, however, it shouldn't be imagined that by creation, completed product is meant. That means the associated products with the fashion industry, in fact, include all components of that product from the initial materials to final product. Therefore, it has to be claimed that, for example, according to legal protect in case of associated creations with the fashion industry, the producer of yarn used in a cloth, in case of having required conditions, enjoys the same rights that the designer of a dress and even the final producer of the product enjoy. After explaining this subject that intellectual property rights have more competence to protect associated products in the fashion industry, this issue should be noticed that protecting fashion and creations related to that is that much capable that the capacities of intellectual property rights facing that, have got a multidimensional attitude. By the mentioned sentence, we mean, despite the attitude of some of some scholars who believe adhere to the aspect and effectiveness of these products and the issue that today fashion profession has turned to an industry and consequently, emphasizing on adding the protection of these products in the framework of industrial property rights, it should be said that due to this, those are right who haven't ignored aesthetic function of this profession while noticing the industrialization of this profession and in 
addition to industry, consider a fashion profession in the field of aesthetic issues and as the result, they consider the capacity of literary and artistic property rights for protecting the mentioned subject worthy. In fact, and as the conclusion, the authorities of fashion profession are recommended to be considered the artist as much as a craftsman and they are recommended to enjoy the teachings of literary and artistic property rights along with industrial property rights.

\section{References}

Azéma, J., \& ET Galloux, J.-C. (2011). Droit de la propriété industrielle. Dalloz.

Bayat, A. (2009). Fashion victim madness. Design and fashion monthly magazine, (12).

Breesé, P. (2004). L'évaluation des droits de propriété industrielle. Gualino.

Clarier, M. (2003). Droit de la propriété intellectuelle. Litec.

Colombe, C. (2011). Fundamental principles of droit d'auteur and neighboring rights in the world. Translation and explanation: Alireza Mohammadzadeh Vadeghani, Mizan publication.

Dehkhoda, A. (1998). Dictionary (Vol. 12). Tehran University Press.

Demulin, P. (2007). Droit de la propriété industrielle. PUF.

Desbois, H. (1992). Le droit d'auteur en France. Dalloz.

Drexl, J. (2001). Les Principes de protection des intérêts diffus ET des biens collectifs: quel ordre public pour les marchés globalisés? Revue de droit privé de l'université Ottawa, (107).

Dupont- Delestraint, P. (2008). Droit de la propriété littéraire et artistique. Dalloz.

Ghafouri Zeinab. (2009). Protect for folklore in intellectual property rights. Master's thesis, intellectual property rights, Faculty of Law, Shahid Beheshti University.

Habibi Dargah, B. (2009). Folklore rights (folklore). Mojed publication.

Imami, A. (2007). Intellectual property rights (Vol. 1). Mizan publication.

Mestre, J. (1998). Droit de la propriété intellectuelle. Dalloz.

Moghimi, K. (2007). Cultural studies in the field of western and Iranian coverage. Social Sciences Journal of Zanjan University, (48).

Mohammadnejad, A. (2005). Fashions. NAsim Alborz magazine, (5).

Montero, E. (1997). Droit de la propriété intellectuelle. Dalloz.

Morteza, S. S. (2008). Droit d'-auteur protection in Iran and international regulations. Journal of Law Excellence, (24).

Pirouzanfard, R. (2009). The role of intellectual property rights in the evolution of Iranian rights. Master's thesis for private law, Islamic Azad University, Faculty of Law, Meybod Branch, Yazd.

Sattar, Z. (2008). Literary and artistic property rights. S.A.M.T University Press.

Tavassoli Gholamabbas. (2003). Modeling in Iranian culture. Social Science Letter of Tehran University, No. 23.

Thriton, N. (2003). Traité de la propriété littéraire et artistique. Litec.

Vivant, M., \& ET Bruguière, J.-M. (2012). Droit d'auteur ET droits voisins. Dalloz.

\section{Copyrights}

Copyright for this article is retained by the author(s), with first publication rights granted to the journal.

This is an open-access article distributed under the terms and conditions of the Creative Commons Attribution license (http://creativecommons.org/licenses/by/4.0/). 